\title{
İş Tatmini, Duygusal Emek ve Tükenmişlik İlişkilerinin Belirlenmesi
}

\author{
To Examine Relationship Between Job Satisfaction, Emotional Exhaution and Emotional \\ Laboring
}

\section{Cengiz MENGENCi ${ }^{1}$}

\begin{abstract}
ÖZET
Bu çalışma kapsamında hizmet sektöründe çalışanların zaman zaman karşılaştıkları tükenmişlik sendromunun duygusal emekleri üzerindeki etkilerinin ve iş tatmini kavramının bu iki kavram arasında oynadığı rolün duygu regülasyon teorisi, kazanımların korunumu teorisi ve duygusal olaylar teorisi temel alınarak belirlenmesi amaçlanmıştır. Çalışmadan elde edilen bilgiler iş tatmini yüksek olan çalışanların daha çok derin davranış ve doğal davranışlarla müşteri hizmetini gerçekleştirdiği buna karşın daha az yüzeysel davranış tercih ettikleri sonucuna varılmıştır. Bunun yanında duygusal tükenme sendromu yaşayan çalışanın müşteriye hizmet verirken daha çok yüzeysel davranış sergilemesi söz konusudur. Son olarak çalışmadan elde edilen sonuçlara göre; iş tatmininin yüzeysel davranış ile duygusal tükenme arasında yarı (partial mediating effect) aracı etkisinin olduğu, derin ve doğal davranışlar ile duygusal tükenme arasında ise tam (full mediating effect) aracı etkisinin olduğunu belirlenmiştir. Bu sonuçlar yüksek iş tatminine sahip çalışanların duygusal tükenme sendromu yaşadıklarında, bu sendromun olumsuz etkisinin örgüt amaçları için kullandıkları duygusal sermayelerine yansıtmayacakları anlamına gelebilecektir.
\end{abstract}

Anahtar Kelimeler: İ̧ tatmini, duygusal tükenme, duygusal emek.

\section{GíRiş}

Günümüz hizmet sektöründe müşteri ilişkileri gittikçe artan oranda önem kazanmaktadır. Sektörde, iyi müşteri ilişkileri, rekabet avantajı olarak kabul görmektedir (Grönroos, 2007). Bu nedenle müşteriyle etkileşime geçen çalışanın olumlu davranış ve duygularla hizmet vermesi önem arz etmektedir. Çalışanın olumlu duygularla müşteriye yaklaşımı, müşterinin örgüte, çalışana ve yapılan hizmete yönelik olumlu duygulara sahip olması anlamına gelebilecektir.

Konu ile ilgili yazın incelendiğinde olumlu davranış ve duygular içeren bir hizmetin kaliteli olduğu (Pugh, 2001; Wolcott ve Burman, 2004), müşterinin olumlu duygularla ayrıldığı (Tsai, 2001) ve örgütten memnuniyet derecesinin artığına yönelik önemli bulgulara ulaşılmaktadır (Matilla ve Enz, 2002). Bu durum işletmeler tarafından çalışanların olumlu duy-

\section{ABSTRACT}

The current study seeks to investigate the relationship between emotional labor, emotional exhaustion and job satisfaction based on emotional regulation theory, emotion regulation theory and conservation of resources theory in service sector. The study was conducted using a survey method of 438 teachers in Yalova. The results confirmed the fact that workers with high job satisfaction would prefer to use more deep and geniune acting but less surface acting when they serve to customer. And also, Structural Equation Modelling analysis results show that there is a positive linear regression relationship between emotional burnout and surface acting. It means when workers suffer from emotional burnout, they may treat to the customer with fake emotional behaviour. Lastly, it was found that job satisfaction has a mediating effect between emotional burnout and emotional laboring. If workers with high job satisfaction suffer from emotional burnout, they may try to reduce the emotional burnout negative effect on their service behaviour.

Keywords: Job satistisfaction, emotional exhaustion, emotional laboring.

gularla hizmet vermeleri ve hizmeti nasıl vereceklerini belirten davranış kalıplarının neler olacağı ile ilgili yönlendirmeler yapmaları demektir (Grandey, 2000). Çalışanların hizmet verirken işletmelerinin istediği duygularla hareket etmeleri yazında duygusal emek olarak tanımlanmaktadır (Morris ve Feldman, 1996).

Hizmet sektöründe önemli olan duygusal emek faktörü, çalışanların zaman zaman iş yeri bazen de sosyal hayatlarında yaşadıkları sorunlar nedeniyle tüketilmekte ve sonuçta çalışanın duygusal tükenmişlik sendromu ile karşılaşmasına neden olabilmektedir. Tükenmişlik sendromu etkisi altındaki çalışan gerçek duygularını hizmet verirken kullanmak yerine işletme tarafından istenilen duygusal içeriği yapmacık tavırlar ile sergileyebilmektedir (Morris ve Feldman, 1996; Pugliesi, 1999; Lin, 2000). Yapmacık davranışlar müşteriler tarafından fark edilmekte ve müşteri memnuniyetini olumsuz yönde etkileyebilmektedir. 
Buradan hareketle, Yalova ilinde hizmet sektöründe çalışanların duygusal tükenme, duygusal emek ve iş tatmin düzeyleri ölçülerek, bu üç faktörün aralarındaki ilişkiler ortaya çıkarılmak ve iş tatmininin aracı etkisinin olup olmadığı belirlenmek istenmektedir. Ayrıca çalışma kapsamında sosyal mübadele, duygusal olaylar ve kaynakların korunumu teorilerinin; iş tatmi$\mathrm{ni}$, duygusal tükenme ve duygusal emek değişkenleri arasındaki ilişkiler belirlenirken geçerliliği de test edilerek yazına katkıda bulunmak istenmektedir. Bunlara ek olarak, iş tatmininin duygusal tükenme ile duygusal emek değişkenleri arasında aracı etkisinin olup olmadığına yönelik, Türkiye ölçeğinde çalışmanın olmaması da söz konusudur. Bu çalışma ile literatürde var olan boşluğunda doldurulması amaçlanmıştır.

\section{DEĞIŞKENLER ARASINDAKI İLIŞKILER}

Günümüzde rekabetin alan değiştirmesi ve daha çok hizmet eksenli olarak gerçekleşmesi çalışanların önemini bir derece daha artırmıştır. Özellikle batı ülkelerinde mal üretiminden hizmet üretimine geçişin yaşanması ile birlikte, rekabet avantajına sahip olmanın ve bu avantajı sürdürebilmenin önemli unsurlarından biri, en iyi müşteri hizmetinin sunulması olarak kabul görmeğe başlamıştır. Müşteriye hizmet sunmadaki beklentilerin artışı çalışanların sadece iddialı fiziksel ve bilişsel işlerin üstesinden gelme sorumluluklarının artışının yanında hizmet verirken kullanılan duygusal ifadelerin tam olarak işyeri tarafından istenildiği şekilde sergilenmesi de gerekmektedir (Shani ve diğ., 2014). İşverenin çalışandan beklentisi olarak belirtilen müşterilere olumlu duygularla hizmet verilmesi durumu ise yazında duygusal emek olarak kabul görmektedir (Domagalski, 1999). Duygusal emek kavramı araştırma başlığı olarak ilk kez Hochschild (1983) tarafından bireyin performans hedeflerine ulaşmak için vücut ve yüz ifadelerini görsel olarak nasıl yönettiğini açıklamak için kullanılmıştır. Bu kavramla daha çok insan ilişkilerinin önem arz ettiği hizmet sektöründe karşılaşılması söz konusudur. Satış elemanları, öğretmenler, uçuş kabin görevlileri ve polis memurluğu mesleklerinde duygusal sermaye meslek üyelerinin psikolojik durumları ve performanslarına etki etmesinin yanında işlerinin ayrılmaz bir parçası olarak kabul görmektedir (Matracci, Newman ve Guy, 2006). Duygusal emek kapsamında müşteri ile etkileşim esnasında kullanılan ve sergilenen davranışların her ne kadar çalışanın karakteri ile yakından ilgili olduğu bilinse de aynı zamanda sosyal, örgütsel ve mesleki normlar tarafından da şekillendirildiği yapılan çalışmalarda ortaya konmuştur (Rafaeli ve Sutton, 1989; Grandey, 2000).
Söz konusu yönlendirmeler davranışın şekilsel içeriğini belirlemekte fakat ne kadar içtenlikle yapılacağı konularında etkili olamamaktadır. Özellikle çalışanın gerçekten hissettikleri ile sergilemesi gereken davranışlar arasında bir çelişki söz konusu olduğunda, duygusal uyumsuzluk ortaya çıkmakta ve çalışan yüzeysel, derin veya doğal davranış yapma tercihi ile karşı karşıya kalmaktadır (Hochschild, 1983). Yapılan çalışmalarda yüzeysel davranış, çalışanın gerçek hisselerini ifade eden davranışlar yerine yapmacık tavırlarla beklenen davranışları sergilemesidir (Steinberg ve Figart, 1999). Derin davranış ise çalışanın sergilediği davranışları gerçekten hissetmeğe çalışma çabası olarak tanımlanmaktadır (Kim, 2008; Grandey, 2000). Çalışan tüm çabasını ortaya koyarak örgüt tarafından istenilen davranış kalıplarını derin veya yüzeysel şekilde yapmak yerine gerçekten hissettiği gibi davranması da söz konusudur. Duygusal harmoni olarak ifade edilen bu durum, çalışanın sergilediği yüz ve vücut davranışlarının taşıdığı duygusal anlamların gerçekten hissettikleri ile doğru yönde olmasıdır (Wong ve Wang, 2009).

Hizmet sektöründe işin bir parçası olarak kabul edilen duygusal emek faktörü ekonomik açıdan da değerlendirilmiştir. Konu ile ilgili yapılan çalışmalarda olumlu duyguların hizmet ile müşteriye yansıtılması müşteri memnuniyeti, tekrar aynı hizmeti alma isteği ve arkadaş ve dostlara işyerinin tavsiye edilmesi gibi işyeri amaçları ile uyuşan sonuçların ortaya çıktığı anlaşıımıştır (Johanson ve Woods, 2008). Çalışmalarda üzerinde durulan asıl konu; müşteriye hizmet verirken çalışanın gerçek ve samimi duygularla davrandığının müşteri tarafından aynı şekilde algılanmasının önemidir (Grandey ve diğ., 2005). Eğer çalışan samimi olarak algılanmaz ise müşteri üzerinde olumlu bir etki oluşturamayacaktır. Daha kötüsü yapmacık davranışlar daha çok müşteriyi kandırma yönünde yapılan manipülatif hareketler sınıfına konulacak ve müşteri olumsuz duygularla işyerinden ayrılacaktır. Diğer bir ifadeyle etkileyici ve olumlu müşteri hizmeti derin ve doğal davranışlarla ortaya konan hizmet olmasının yanında hoşnut kalınmayan müşteri hizmeti de yüzeysel davranışlar ile verilmeye çalışılan hizmet olarak kabul görecektir (Van Dijk ve diğ., 2011). Bu durum işyeri tarafından hizmet çalışanının müşteriye sürekli derin ve doğal davranışlarla hizmet götürmesini beklemesi anlamına gelebilecektir. İşyerinde çalışan eğer ne tür duygularla hizmet vereceğine karar veriyorsa ve bu kişisel gelişimine faydalı oluyorsa, çalışanların sürekli derin ve doğal davranışlarla hizmet görmelerinin iş tatminlerini de olumlu yönde etkilediği yapılan çalışmalarla belirlenmiştir (Tolich, 1993; Adelmann, 1995). 
Buradan hareketle iş tatmini kavramı ile ilgili çaIışmalar yakından incelendiğinde, bu kavramın, çalışanın işine karşı olumlu ya da olumsuz hissettiği tüm duygular olarak tanımlanmaktadır (Wegge ve diğ, 2007; Makanjee ve diğ, 2006). İş tatminini bazı araştırmacılar çalışanın işyerinden beklentilerinin karşılanma düzeyinin bir yansıması olarak görmektedir (Testa, 2001). Bu kavram ayrıca çalışanın elde ettikleri ile elde etmek istediklerini karşılaştırdığında elde ettiği sonuca bağlı olarak kişinin işine gösterdiği duygusal reaksiyon olarak tanımlanmaktadır (Crany ve diğ., 1992; Fields, 2002). Yapılan tanımlardan çalışanın işinden tatmin olabilmesi iş yerinden bir dizi beklentisinin karşılanmasına bağlanmaktadır. Bu beklentiler Porter (1974) tarafından ücret, otonomi, ayrıcalıklar ve kariyer olarak sıralanmaktadır. Bunlara ek olarak, çalışanın işine karşı taşıdığı tüm duyguların ücret, iş güvencesi, iş yeri desteği, sosyalleşme ve ilerleme gibi bazı faktörler tarafından şekillendirildiğini gösteren önemli bulgulara da ulaşılmaktadır (Parnell ve Crandall, 2003). Diğer yandan araştırmacılar düşük iş tatmin düzeyinin iş yerinde neden olduğu sorunlar üzerinde de durmuşlardır (George ve Jones, 1997; Ostroff, 1992; Testa, 2001; Vandenberg ve Lance, 1992; Williams ve Anderson, 1991). Yapılan çalışmalarda iş tatmin düzeyi düşük çalışanların çalışan devir hızının yüksek olduğu, işe geç geldiği, performanslarının ve örgütsel bağlılık düzeylerinin düşük olduğuna vurgu yapılmaktadır. Bu bilgiler hizmet sektöründe çalışanların düşük iş tatmin düzeyine sahip olması sonuç olarak işveren beklentisinin istenilen düzeyde karşılanamayacağını ifade edecektir.

Çalışanın hizmet sektöründe iş yeri tarafından beklenen davranış kalıpları ile hizmet vermesi oldukça talepkar bir durumdur. Sürekli duygularını kontrol eden ve istenilen şekillerde olup olmadığını sorgulayan bir çalışanın üzerinde daha fazla stres oluşması kaçınılmaz sonuçlardandır (Hochschild, 1983). Hizmet sektöründe çalışanların duygularına hakim olmaya çalışmaları yazında duygu regülasyonu teorisi ile açıklanmaktadır. Bu teori duygusal regülasyon kavramını bireyin hangi duyguyu, ne zaman ve nasıl sergileyeceğini belirlediği bir süreç olarak tanımlamaktadır (Gross, 1998b). Gross (1998b) duygu regülasyonunu öncül odaklanma ve tepkisel odaklanma olmak üzere iki süreç olarak kabul etmektedir. Illk süreç, bireyin tüm düzenlemeleri ya da durum değerlendirmelerini duygusal tepkilerinden önce gerçekleştirdiği öncül odaklanma dönemidir. Bu dönem derin davranış olarak kabul görmektedir. İkinci süreç ise tutarlı ve gözlemlenebilir şekilde duyguların düzeltilip şekil verildiği tepkisel odaklanma dönemidir. Bu durum yüzeysel davranış olarak tanımlanmaktadır.
İş tatmini ile duygusal emek ilişkisini inceleyen araştırmalarda, doğrudan halkla temasta olan kişi ya da işlerde çalışanlar, eğer hizmet alanın duygularına şekil verebiliyor ve kontrolü kendinde hissediyorlarsa, bu durumun çalışanı olumlu yönde etkilediği ifade edilmektedir (Wharton, 1996). Bunlara ek olarak eğer çalışan güçlü bir şekilde iş yapış biçimi ile rolünü ayrıca duygusal emeğini nasıl kullanacağına karar verebiliyorsa, çalışanın iş tatmin düzeyinin arttığına yönelik önemli bulgulara konu ile ilgili yapılan çalışmalarda rastlamak mümkündür ( Ericson ve Wharton, 1995). Adelmann (1995) çalışmasında duygularını yüksek düzeyde regüle eden ve derin ya da doğal davranışlarla müşteri karşılama görevini yerine getiren çalışanların, yüzeysel davranışlarla bu görevi yerine getiren çalışanlardan daha fazla işlerinden tatmin olduklarını belirlemiş̧tir. Diğer bir çalışmada Abraham (1998) yüzeysel davranışlarla hizmet veren çalışanların iş tatminleri ile duygusal emekleri arasında negatif bir ilişki olduğu sonucunu elde etmiştir. Yapılan çalışmalarda iş tatmini ile duygusal emek arasında farklı sonuçların elde edilme nedeni bazı çalışmalarda duygusal emeğin yüzeysel davranış, bazılarında ise derin davranış olarak değerlendirilmesinden kaynaklandığı anlaşılmaktadır. İş tatmini ile duygusal emek kavramları ile ilgili verilen tüm bilgiler ışığında aşağıdaki hipotezleri ileri sürmek mümkün görünmektedir.

$\mathrm{H}_{1}$ : Hizmet sektöründe çalışanların derin davranışları ile iş tatmini arasında pozitif doğrusal bir iliş̧i vardır.

$\mathrm{H}_{2}$ : Hizmet sektöründe çalışanların doğal davranışları ile iş tatminleri arasında pozitif doğrusal bir ilişki vardır.

$\mathrm{H}_{3}$ : Hizmet sektöründe çalışanların yüzeysel davranışları ile iş tatminleri arasında negatif doğrusal bir ilişki vardır.

Hizmet sektörü oldukça talepkar bir yapıya sahiptir. Memnun edilmesi oldukça zor müşterilerle karşılaşan ve onları istenilen davranış kalıpları ile hizmet vererek memnun etmeye çalışan birey, oldukça yüksek oranda çaba harcamak zorunda kalmaktadır. Harcanan çabanın sonucunda istenilen müşteri memnuniyetinin karşılanamaması, çalışanın duygusal iniş ve çıkşlara, pozitif veya negatif duygu değişimleri yaşamasına neden olurken, duygusal anlamda tüm sermayesini tüketmesi sonucunu ortaya çıkarabilmektedir.

Tükenmişlik kavramı ilk olarak konu ile ilgili yazına Freudenberger (1975) tarafından kazandııımıştır. Bu kavram araştırmacı tarafından çalışanın fiziksel, duygusal ve mental olarak yorgun düşmesi ve bunun sonucunda başarıda azalma, yabancılaşma ve işe olan ilginin kaybedilmesi şeklinde tanımlanmıştır (Tümkaya, Cam ve Çavuşoğlu, 2009). 
Tükenmişlik kavramı ile ilgili önemli bir diğer çalışma Maslach ve arkadaşları (1986) tarafından gerçekleştirilmiştir. Maslach (1986) tükenmişliği üç farklı kişisel durumu barındıran bir yapı olarak algılamaktadır. Bunlardan ilki, bireyin duygusal tüm gücünü yitirmesi durumu duygusal tükenme; ikincisi, diğer kişilerden uzak durma tutumu, yabancılaşma ve son olarak işinde düşük düzeyde başarı yaşanması ise azalan kişisel başarı olarak tanımlanmaktadır (Maslach ve Jackson, 1986). İşten ayrılma, artan ayrılma niyeti, olumsuz iş yeri davranışları ve düşük performans ise örgüte yansıyan yönleri olarak ifade edilmektedir (Cameron, Horsburgh, ve ArmstrongStassen, 1994; Jackson, Schwab, ve Schuler, 1986; Lee ve Ashforth, 1996; Wolpin, Burke, ve Greenglass, 1991; Wright ve Bonett, 1997; Wright ve Cropanzo, 1998).

Tükenmişlik kapsamında yapılan çalışmalarda araştırmacılar, bu kavramın en temel belirleyicisinin duygusal tükenme olduğuna işaret etmektedirler (Cordes ve Dougherty, 1993; Schaufeli, Maslach, ve Marek, 1993). Bu nedenle çalışma kapsamında sadece duygusal tükenme boyutu inceleme altına alınmıştır. Çalışanların sürekli müşteri ile karşı karşıya gelmesi ve duygularını işletmenin istediği biçimde düzenlemesi oldukça yorucu bir faaliyettir (Rafaeli ve Sutton, 1987). Böyle bir düzenleme kişinin duygusal emeğini tüketmesi ve stres düzeyinin artması ile birlikte tükenmişlik sendromu yaşaması söz konusu olabilmektedir (Morris ve Feldman, 1997; Pugliesi, 1999; Lin, 2000).

Duygusal olaylar teorisi bireyin yaşadığı duygusal olayların yapısal nedenleri ve sonuçları üzerine yoğunlaşmaktadır (Weiss ve Crapanzano, 1990). Bu teori çalışanın yaşadığı olaylara verdiği duygusal tepkilerin davranış ve tutumlarına olan etkilerini incelemektedir. Konu ile ilgili çalışmalara bakıldığında yaşadığı olumsuz olayların olumlu olaylardan daha fazla çalışan psikolojisini etkilediği ve bu negatif etkinin çalışan davranışlarına yansıdığı belirtilmektedir (Taylor, 2002). Bussing ve diğ. (2000) yaptıkları çalışmalarında kişilerin yaşadıkları olumsuz olaylar sonrasında eşleri ile çatıştıkları sonucuna ulaşmıştır. Schilling (2003) kişinin kavga ve çatışmaya yatkın olma nedeninin yaşanan olumsuz durumlardan kaynaklandığını tespit etmiştir. Bunlara ek olarak Kohn ve Schooler (1982)'ın yaptıkları çalışmalarında kişinin çalıştığı iş yerindeki aşırı iş beklentilerinin ve zaman baskısının çalışan üzerinde strese neden olduğuna yönelik önemli bulgulara ulaşmışlardır. Ortaya çıkan stres, aşırı iş yükü ve bunun yanında rol karmaşası gibi unsurlar ilk önce bireyin duygusal sermayesinin tüketmesine ve daha sonra tükenmiş- lik sendromu yaşamasına neden olan faktörlerdir. Hochschild (2003) çalışmasında çalışanların işyeri tarafından istenildiği şekilde duygularını kontrol etmeleri ve belli standartlarda davranış kalıpları ile hizmet vermeye çalışmalarının kişinin duygusal sermayesini tükettiği, stres düzeyini artırdığı ve sonuçta duygusal tükenme sendromu yaşamasına neden olduğunu belirtmiştir. Tüm bu bilgiler çalışanın duygusal emeğini aşırı derecede kullanması sonrasında duygusal tükenme sendromu ile karşı karşıya kalabileceği anlamına gelebilecektir. Çalışanın duygusal sermayesinde kullanabileceği emeğinin kalmaması olumsuz duygularını işyerindeki davranışlarına taşıyacağı ve hizmet sektöründe önem taşıyan doğal ve derin davranışlar yerine yüzeysel davranışlarla müşteriyi memnun etmeye çalışacağı anlamına gelebilecektir (Weiss ve Crapanzano, 1996).

Tüm verilen bilgiler doğrultusunda aşağıdaki hipotezleri ileri sürmek olası görünmektedir:

$\mathrm{H}_{4}$ : Hizmet sektöründe, derin davranış ile duygusal tükenme arasında negatif doğrusal bir ilişki vardır.

$\mathrm{H}_{5}$ : Hizmet sektöründe, doğal davranış ile duygusal tükenme arasında negatif doğrusal bir ilişki vardır.

$\mathrm{H}_{6}$ : Hizmet sektöründe, yüzeysel davranış ile duygusal tükenme arasında pozitif doğrusal bir ilişki vardır.

Hizmet sektöründe önemli olan çalışanın psikolojik açıdan kendini iyi hissettiğinde değil, her zaman aynı düzeyde performans göstermesi ve bir istikrar sergilemesidir. Bunun nedeni, müşterinin hizmeti her aldığında aynı düzeyde bir kalite beklentisi içerisinde olması ve eğer bu kalite sürdürebilir olursa hizmet almaya devam etmek istemesidir.

Peki, hizmet sektöründe duygusal anlamda tükenen bir çalışan her durumda aynı seviyede hizmet kalitesini nasıl devam ettirecektir? Bu noktada, sorunun yanıtı kaynakların korunumu teorisi ile verilebilir. Kazanımların korunumu teorisi bir motivasyon teorisi olarak kabul görmekte ve temel ilkesi bireyin kendi intiyacı olan kaynakları arayacağını, elde etmeye çalışacağını, artırmak isteyeceğini ve korumak için her türlü olumsuz durum ile başa çıkmaya motive olacağını belirtmektedir (Hobfoll, 1989; Westman ve diğ., 2005). Bu kapsamda bireyin elde etmek isteyeceği kaynaklar maddi hedefler (araba, ev ve lüks tüketim eşyaları), statüler (ebeveyn rolü, sosyal bir çevre içinde olma), kişisel özellikler (yetenek ve karakter) ve enerji olarak sıralanmaktadır (Hobfoll, 1998; 2001). 
Buradan hareketle hizmet sektöründe çalışan bireyin ücret, iş güvencesi, iş yeri desteği, sosyalleşme ve ilerleme gibi iş tatminini oluşturan faktörleri korumaya çalışacağını; duygusal emeğini sonuna kadar kullansa ve duygusal tükenme sendromu ile karşı karşıya olsa da olumsuz duygularını müşteriye hizmet verirken yansıtmak yerine mümkün olan tüm gücünü kullanarak özveri ile görev ve sorumluluklarını yerine getireceğini beklemek mümkündür (Brotheridge ve Grandey, 2002). lebilir:

Bu bilgiler ışığında aşağıdaki hipotez ileri sürü-

$\mathrm{H}_{7}$ : Hizmet sektöründe iş tatmini kavramının duygusal tükenme ile duygusal emek arasında pozitif aracı etkisi vardır.

Yukarıda oluşturulan hipotezler üretilen üç model kapsamında sınanacaktır. Bunun nedeni aracı etki araştırmasında Baron ve Kenny (1986) tarafından önerilen yöntemin modeller şeklinde daha görsel duruma getirilmesinden kaynaklanmaktadır. Illk model; iş tatmini ile duygusal emek ilişkisi üzerine, ikinci model; duygusal tükenme ile duygusal emek ilişkileri ve son model; iş tatmininin duygusal tükenme ile duygusal emek değişkenleri arasındaki aracı etkinin ölçümüne yönelik oluşturulmuştur.

Araştırmada kullanılacak modeller.

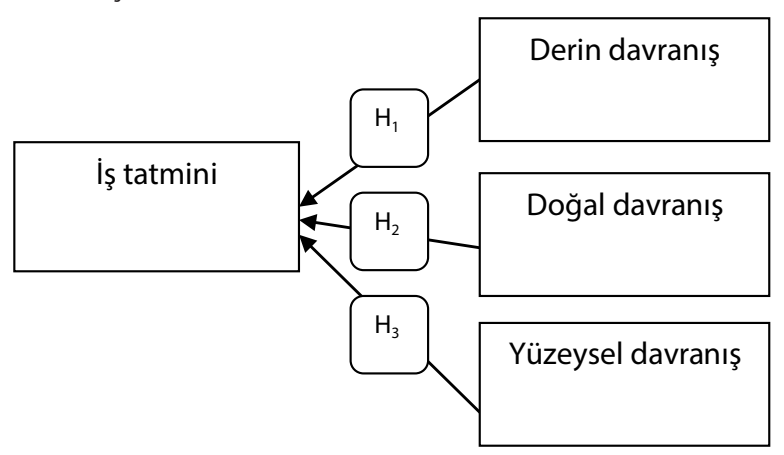

Model 1: Iş̧ tatmini ile Duygusal Emek ilişkileri

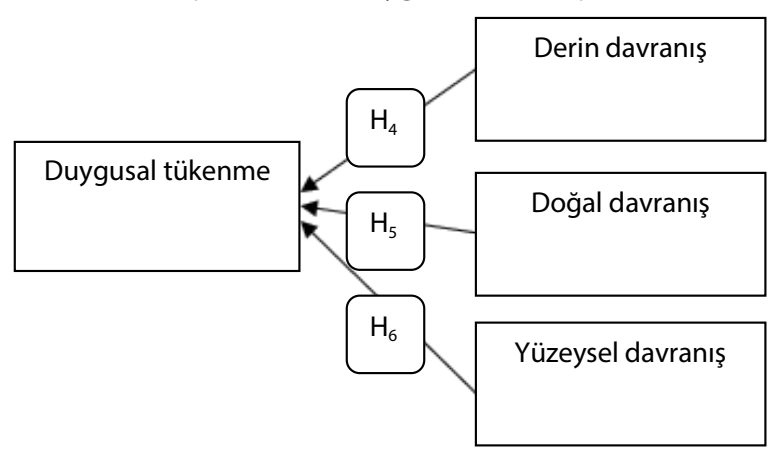

Model 2: Duygusal Tükenme ile Duygusal Emek İlişkileri

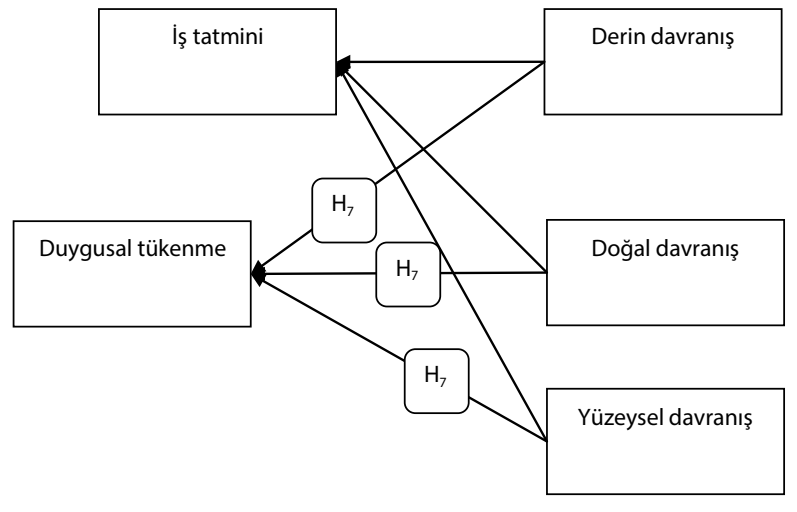

Model 3: İş Tatmininin Duygusal Tükenme ile Duygusal Emek Arasındaki Aracı Etkisi

\section{YÖNTEM}

Araştırma kapsamında oluşturulan üç modeli test etmek amacıyla demografik değişkenlerin yanı sıra iş tatmini, duygusal tükenme ve duygusal emek kavramları için bir anket düzenlenmiştir. Araştırmanın evrenini, Yalova III Merkezinde bulunan devlete bağIı Anaokul, Illköğretim Okulu ve Liselerden oluşan ve toplam 9 okulda görev yapan öğretmenler oluşturmaktadır. Bu araştırma, toplam 550 öğretmen arasından kolayda örnekleme (convenience sampling) yöntemine göre seçilmiş toplam 438 öğretmenin oluşturduğu örneklem üzerinde yürütülmüştür. Araştırmaya katılan öğretmenlerin \%48,6'si kadın, \%51,4'i erkeklerden oluşmaktadır. Öğretmenlerin \%15'i 25 ve altı yaş aralığında olup, \%28,1'i 26-35, \%35,2'si 36-45 yaş aralığındadır. 46 ve üzeri yaş aralığında olan öğretmenlerin oranı \%33,3'dür. Öğretmenlerin mesleklerindeki kıdemlerine göre dağılımlarına bakıldığında \%53,2'inin 1-5 yıl, \%23,1'inin 6-10 yıl, \%9,6'sının 11-15, $\% 14,2$ 'sinin 16 yıl ve üzeri kıdeme sahip olduğu görülmüştür. Araştırmaya katılan öğretmenlerin $\% 82,6$ 'sı evli, \%17,4'ü bekardır. Ayrıca katılımcıların; \%46,8'i lise, $\% 12,1^{\prime i}$ ortaokul, $\% 36,8^{\prime}$ i ilkokul ve $\% 4,3$ 'ü anaokulu öğretmenlerinden oluşmaktadır.

\subsection{Veri Toplama Araçları}

Verilerin toplanmasında, demografik bilgiler dışında, çalışanların iş tatmini, duygusal tükenme ve duygusal emek düzeylerini belirlemek amacıyla üç farklı anketten yararlanılmıştır.

\subsection{1. İş Tatmini Ölçeği}

Bu anket, çalışanların iş tatmini düzeylerini belirlemek için Spector (1985) tarafından geliştirilmiş̧ir. Türkçeye Kula (2011) tarafından uyarlanan ve 9 sorudan oluşan bu ölçeğin derecelendirilmesinde beş'li Likert tipi ölçek kullanılmıştır. Bu anketteki sorulara verilen cevaplar 1'den 5'e kadar değişen puanlarla değerlendirilmiş olup (1) kesinlikle katılmıyorum, (2) 
katılmıyorum, (3) kısmen katılıyorum, (4) katılıyorum ve (5) tamamen katılıyorum şeklinde düzenlenmiştir. Anket için yapılan güvenilirlik analizinde Cronbach Alpha katsayısı 0.85 olarak bulunmuştur. Çarpıklık (skewness) ve basıklık (kurtosis) değerleri -1 ve +1 arasında bulunmuş olup, dağılım normaldir. Kullanılan bu ölçeğe uygulanan doğrulayıc faktör analizi sonucunda faktör yükleri .63 ila .76 arasında elde edilmiştir. Ankette bulunan üç sorunun faktör yükleri .50 altında olduğundan modelden çıkarılmış olup, iş tatmini 6 soruyla ölçülmüştür.

\subsubsection{Duygusal Tükenme Ölçeği}

Araştırmaya katılan çalışanların duygusal tükenme düzeylerinin belirlenebilmesi için; 1986 yılında Maslach ve Jackson tarafından geliştirilen ve Ergin (1992) tarafından Türkiye'de geçerlik ve güvenirlik çaIışması yapılmış olan Maslach Tükenmişlik Ölçeği'nin, 9 sorudan oluşan Duygusal Tükenme alt ölçeği kullanılmıştır. Ölç̧ekte yer alan ifadelere 5 'li Likert formatında yanıt istenmiştir. Buna göre; $5=$ Her zaman, 1 = Hiçbir zaman'ı ifade etmektedir. Anket için yapılan güvenilirlik analizinde Cronbach Alpha katsayısı 0.87 olarak bulunmuştur. Çarpıklık (skewness) ve basıklık (kurtosis) değerleri -1 ve +1 arasında bulunmuş olup, dağılım normaldir. Duygusal tükenme ölçeğine doğrulayıc faktör analizi uygulandığında faktör yükleri .60 ila .77 arasında oluşmuştur. Ankete dahil edilen bir sorunun faktör yükü .50 altında olduğundan modelden çıkarılmış olup, iş tatmini 8 soruyla ölçülmüştür.

\subsubsection{Duygusal Emek Ölçeği}

Çalışanların duygusal emek davranışlarını belirlemek amacıyla Duygusal Emek Ölçeği, Diefendorff ve arkadaşları (2005) tarafından, Grandey (2003) ve Kruml ve Geddes'ın (2000) duygusal emek ölçeklerinin bazı maddelerinin alınarak uyarlanması ve bazı maddelerin ise geliştirilmesiyle oluşturulmuştur. Ölçek, Türkiye'de Basım ve Beğenirbaş (2012) tarafından güvenilirlik ve geçerlilik analizlerini yapmak için uygulanmıştır. Yapılan çalışma sonucunda ölçeğin kullanılabileceğine yönelik sonuçlar elde edilmiştir. Bu ölçek 13 sorudan oluşmakta ve yüzeysel davranış, derin davranış ve doğal davranış olmak üzere üç boyutu içermektedir. Katılımcılar ölçek maddelerini beşli Likert Ölçeği yardımıyla değerlendirmişlerdir (1=Hiçbir Zaman, 5= Her Zaman). Anket için yapılan güvenilirlik analizinde Cronbach Alpha katsayıları sırasıyla $.83, .87, .84$ olarak bulunmuştur. Çarpıklık (skewness) ve basıklık (kurtosis) değerleri -1 ve +1 arasında bulunmuş olup, dağılım normaldir. Ölçeğe doğrulayıcı faktör analizi uygulandığında, faktör yükleri .57 ile .89 arasında elde edilmiştir. Varyans açılama oranı \%62 olarak bulunmuştur.

\subsubsection{Verilerin Analizi}

Verilerin değerlendirilmesinde IBM SPSS 21,0 istatistikî değerlendirmeler ve Yapısal Eşitlik Modellemesi için AMOS 16,0 programı kullanılmıştır. Yapısal Eşitlik Modelleme birkaç değişkenin aynı anda yapısal bir modelde ilişki açısından analiz edilmesini sağlayan (Wan, 2002) ve ölçüm hatalarını göz önünde bulunduran bir analiz metodudur (Byrne, 2006).

Bu araştırmada, istatistikî anlamlılık düzeyi $p<0,5$ olarak kabul edilmiştir. Yapısal Eşitlik Modeli analiz uygulanan çalışmalara bakıldığında uyum istatistikleri (goodness-of-fit) hakkında değişik parametreler kullanılmıştır. Hangi parametrelerin kullanılması gerektiği hakkında bir fikir birliği olmasa da, birkaç parametrenin birlikte kullanılması tavsiye edilmektedir. Bu bağlamda, en azından üç uyumluluk (fit) test grubundan birer adet kullanılmalıdır (Garson, 2009). Literatürde en çok kullanılan uyum istatistik değerleri şunlardır: $\chi^{2}-p-\chi^{2} / d f$, RMSEA-PCLOSE, TLI-CFI değerleri ile HOLTER Index değeridir (Uryan, 2010: 70-73; Kula, 2010: 65-74). Uyum istatistiklerinin olması gereken değer aralıkları $x^{2}$ ne kadar küçük olursa iyidir; $\mathrm{p} \geq$ 0.05; $\mathrm{X}^{2} / \mathrm{df} \leq 4$; RMSEA: 05 $\geq$ değer $\leq, 08$; kabul edilebilir $\leq, 05$ iyi; PCLOSE $\geq 0.05$; TLI.90 $\leq$ değer < 0.95; kabul edilebilir $\geq 0.95$ iyi; CFI $.90 \leq$ değer $<0.95$; kabul edilebilir $\geq 0.95$ iyi ve HOLTER index değeri $75 \leq$ değer < 200; kabul edilebilir $\geq 200$; iyi olarak tanımlanmaktadır (Schumacker ve Lomax, 2004: 82) .

Anket dönüşlerinden elde edilen ham bilgileri analize hazır hale getirmek amacıyla bu bilgilere kayıp veri incelemesi yapılmıştır. Yapılan incelemede kayıp veri içermediği, aşırı uç değerlerin olmadığı ve basıklık ve çarpıklı değerlerinin $+1,5$ ila $-1,5$ arasında olduğu, bununda normal değer aralığı olmasından dolayı tüm verilerin normal bir dağılım gösterdiği kabul edilmiştir.

Kayıp veri incelemesi sonrasında faktör analizi gerçekleştirilmiştir. Faktör analizi sonuçlarına göre faktörlerin iş tatmini, duygusal emek, derin, doğal ve yüzeysel davranış yapıları altında toplandığı belirlenmiştir. Güvenilirlik ve betimsel istatistik değerleri Tablo 1'de görüldügüu gibidir. Tablo 1 incelendiğinde tüm değişkenler arasında korelâsyon ilişkileri bulunduğu ve güvenilirlik değerlerinde oldukça iyi oldukları fark edilmektedir. 
Tablo 1: Betimsel İstatistik Değerleri

\begin{tabular}{|l|r|r|r|r|r|r|r|r|}
\hline & $\begin{array}{c}\text { Ortalama } \\
\text { Değer }\end{array}$ & $\begin{array}{c}\text { Standart } \\
\text { Sapma }\end{array}$ & Cronbach & $\begin{array}{c}\text { Işs } \\
\text { Tatmini }\end{array}$ & $\begin{array}{c}\text { Duygusal } \\
\text { Tükenme }\end{array}$ & $\begin{array}{c}\text { Yüzeysel } \\
\text { Davranış }\end{array}$ & $\begin{array}{c}\text { Derin } \\
\text { Davranış }\end{array}$ & $\begin{array}{c}\text { Doğal } \\
\text { Davranış }\end{array}$ \\
\hline İş tatmini & 3,7648 &, 799 &, 852 & 1 & & & & \\
\hline Duygusal tükenme & 2,5793 &, 877 &, 873 &,$- 554^{* *}$ & 1 & & & \\
\hline Yüzeysel davranış & 2,6176 &, 881 &, 837 &,$- 187^{* *}$ &, $351^{* *}$ & 1 & & \\
\hline Derin davranış & 3,5668 &, 949 &, 872 &, $265^{* *}$ &,- 092 &, $190^{* *}$ & 1 & \\
\hline Doğal davranış & 4,2009 &, 799 &, 843 &, $362^{* *}$ &,$- 201^{* *}$ &,$- 286^{* *}$ &, $222^{* *}$ & 1 \\
\hline
\end{tabular}

(Not : **. Correlation is significant at the 0.01 level 2-tailed).

\section{BULGULAR}

Çalışma kapsamında ilk olarak Model 1'de ortaya konulan ilişkiler analiz edilmiştir. Yapılan bu analiz sonuçlarına ait Yapısal Eşitlik Modellemesi sonuçları Şekil 1'de görüldüğü gibidir. Bu sonuçlar incelendiğinde iş tatmininin yüzeysel davranış ile negatif doğrusal $(r=-, 25)$, derin davranış $(r=.28)$ ve doğal davranış $(r=.33)$ ile istatistiksel düzeyde anlamlı pozitif doğrusal ilişkilerinin olduğu görülmektedir. Elde edilen bu sonuçlar ileri sürülen $\mathrm{H}_{1}, \mathrm{H}_{2}$ ve $\mathrm{H}_{3}$ hipotezlerini doğrular niteliktedir.

Modelin yapısal eşitlik modelleme uyum değerlerine bakıldığında tüm değerlerin istenilen aralıklarda olduğu ve iyi uyuma sahip olduğu anlaşılmaktadır. Model 1'in yapılan analiz sonucunda elde edilen uyum değerleri $x^{2}: 389,189, p:, 000, x^{2} / d f: 2,41$, RMSEA: ,062, PCLOSE: ,003, TLI: ,928, CFI: ,940 ve HOLTER Index: 210 olarak elde edilmiştir.

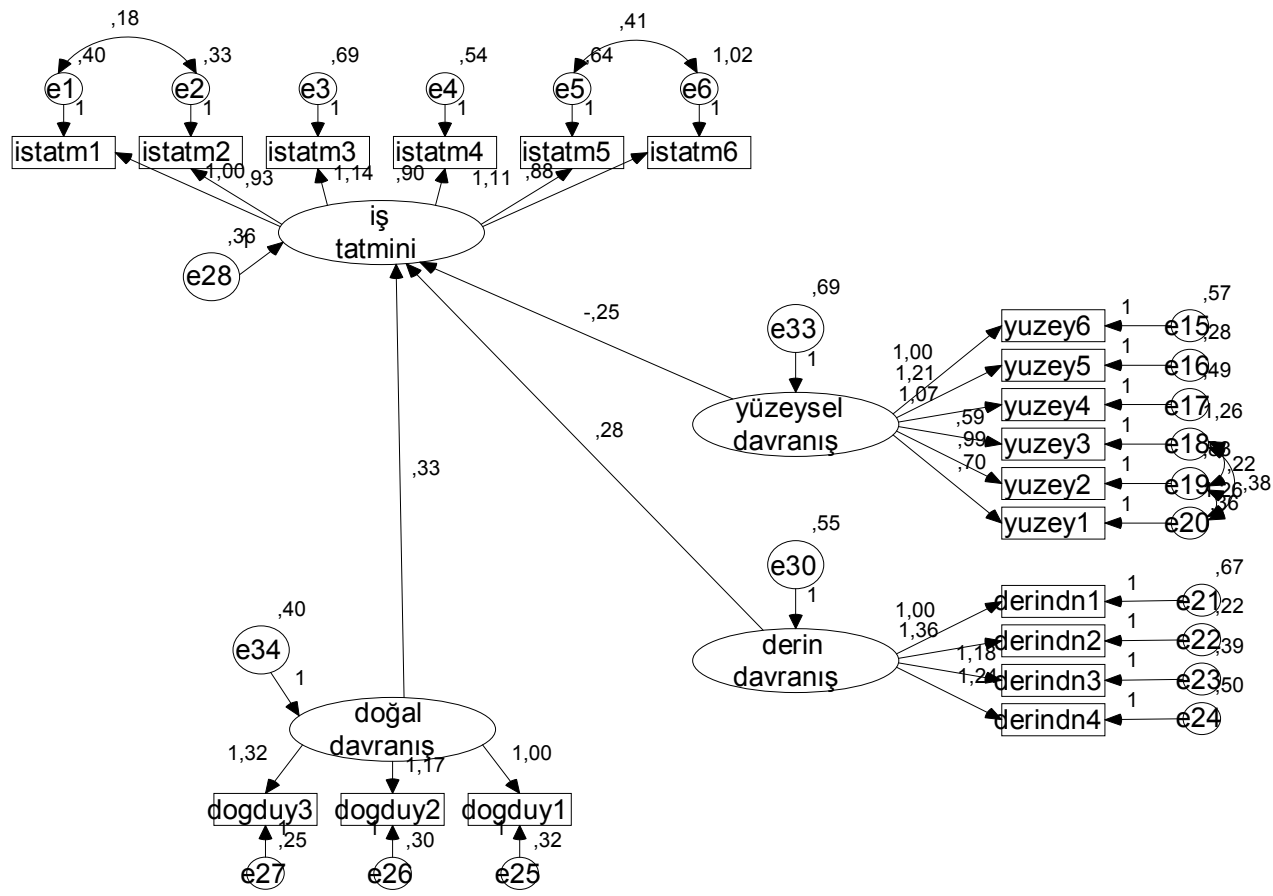

Şekil 1: İş tatmini ve Duygusal Emek Değişkenleri İlişsileri Yapısal Eşitlik Sonuçları

Analizler kapsamında ikinci olarak incelenen Model 2'de ileri sürülen duygusal tükenme ve duygusal emek değişkenleri arasındaki ilişkilerdir. Elde edilen sonuçlar $\mathrm{H}_{4}, \mathrm{H}_{5}$ ve $\mathrm{H}_{6}$ hipotezlerinin kabul edildiğini göstermektedir. Şekil 2'de görüldüğü gibi duygusal tükenme değişkeninin yüzeysel davranış ile pozitif doğrusal $(r=$,39), derin davranış ile negatif doğrusal $(r=-, 15)$ ve son olarak doğal davranış ile istatistiksel düzeyde anlamlı negatif doğrusal $(r=-, 07)$ ilişkilerinin olduğu belirlenmiştir. Model 2'nin yapılan analiz sonucunda elde edilen uyum değerleri $X^{2}: 417,155$, p:000, X²/df: 2,25, RMSEA: ,055, PCLOSE: ,016, TLI: ,935, CFI: ,944 ve HOLTER Index: 237 olarak elde edilmiştir.

Son olarak çalışma kapsamında Model 3 ile ileri sürülen ilişkiler inceleme altına alınmıştır. Şekil 3 incelendiğinde iş tatmininin duygusal tükenme ile duygusal emek arasında aracı etkisinin olduğu anlaşılmaktadır. Aracı etki araştırması Baron ve Kenny (1986) tarafından önerilen ara değişken koşulları kapsamında analiz edilmiştir. Bu yönteme göre, aracılık etkisinden söz edilebilmesi için üç şartın var olması gerekmektedir: 


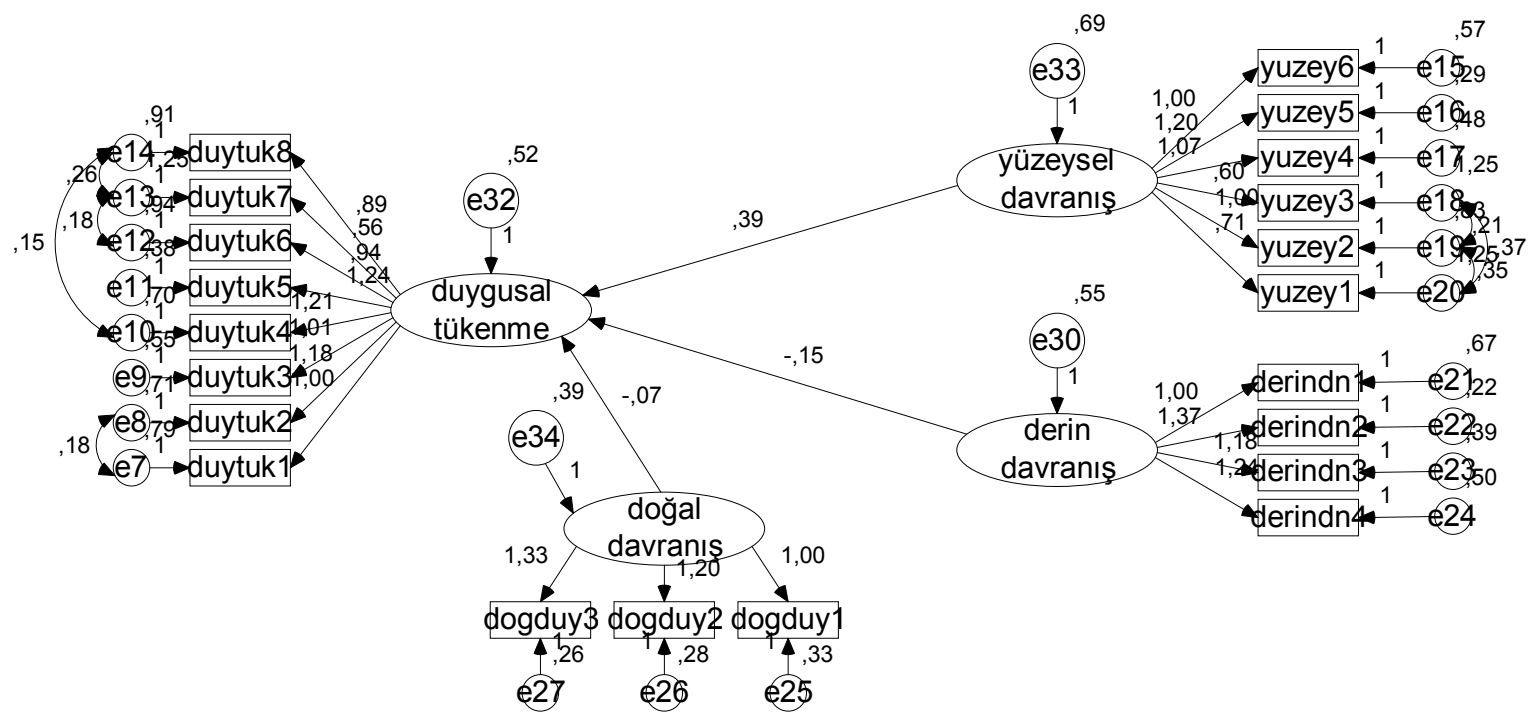

Şekil 2: Duygusal Tükenme ile Duygusal Emek İlişkileri

(1) Bağımsız değişkenin aracı değişken üzerinde bir etkisi olmalıdır.

(2) Bağımsız değişken bağımlı değişken üzerinde etkili olmalıdır.

(3) Aracı değişken ikinci adım sonrası analize dâhil edildiğinde, bağımsız değişkenin bağımlı değişken üzerindeki regresyon katsayısı düşerken, aracı değişkenin de bağımlı değişken üzerinde anlamlı bir etkisi olmalıdır.

Bu üç koşul yapılan analiz içinde arandığında her üç koşulunda analiz çerçevesine dâhil edildiği anlaşılmaktadır. Illk olarak, bağımsız değişkenin aracı değişken üzerindeki etkisi Model 3'e bakıldığında duygusal tükenmenin iş tatmini üzerinde negatif bir etkisinin olduğu anlaşılmaktadır. İkinci koşul ise Model 2'ye bakıldığında duygusal tükenmenin derin davranış üzerinde etkisi görülebilmekte ve bu koşulda sağlanmaktadır. Ve son olarak yine Model 3'e bakıldığında Model 2'de bağımsız değişkenin bağımlı değişken üzerindeki etkisinin Model 3'de görüldüğü gibi aracı değişken devreye girdiğinde düştüğü sonucu elde edilmektedir. Bu sonuçlar iş tatmini değişkeninin duygusal tükenme ile yüzeysel davranış arasında yarım ve duygusal tükenme ile derin ve doğal davranış arasında tam aracı etkisinin olduğunu göstermektedir (Baron ve Kenny, 1986).

Sonuç olarak iş tatmini kavramının hizmet sektöründe duygusal tükenme ile duygusal emek arasındaki aracı rolünün olduğu bilgisine ulaşıımıştır. Bu sonuç ileri sürülen $\mathrm{H}_{7}$ hipotezi desteklenmektedir. Çalışma kapsamında ileri sürülen tüm hipotezler elde edilen sonuçlar tarafından desteklenmektedir.

Yapısal eşitlik modellemesi kapsamında iş tatmininin duygusal tükenme ile duygusal emek kavramları arasındaki aracı etkisini belirlemeye yönelik oluşturuIan modelin uyum istatistiklerine bakıldığında; Model 3'ün $x^{2}: 648,159, p:, 000, x^{2} / d f:$ 2,01, RMSEA: ,050, PCLOSE: ,019, TLI: ,934, CFI: ,942 ve HOLTER Index: 249 değerlerine sahip olduğu belirlenmiştir. Bu modelinde referans kabul edilen değerlerle karşılaştırılması yapıldığında iyi uyum istatistikî değerlerine sahip olduğu kabul edilebilir (Joreskog ve Sorbom, 2001) 


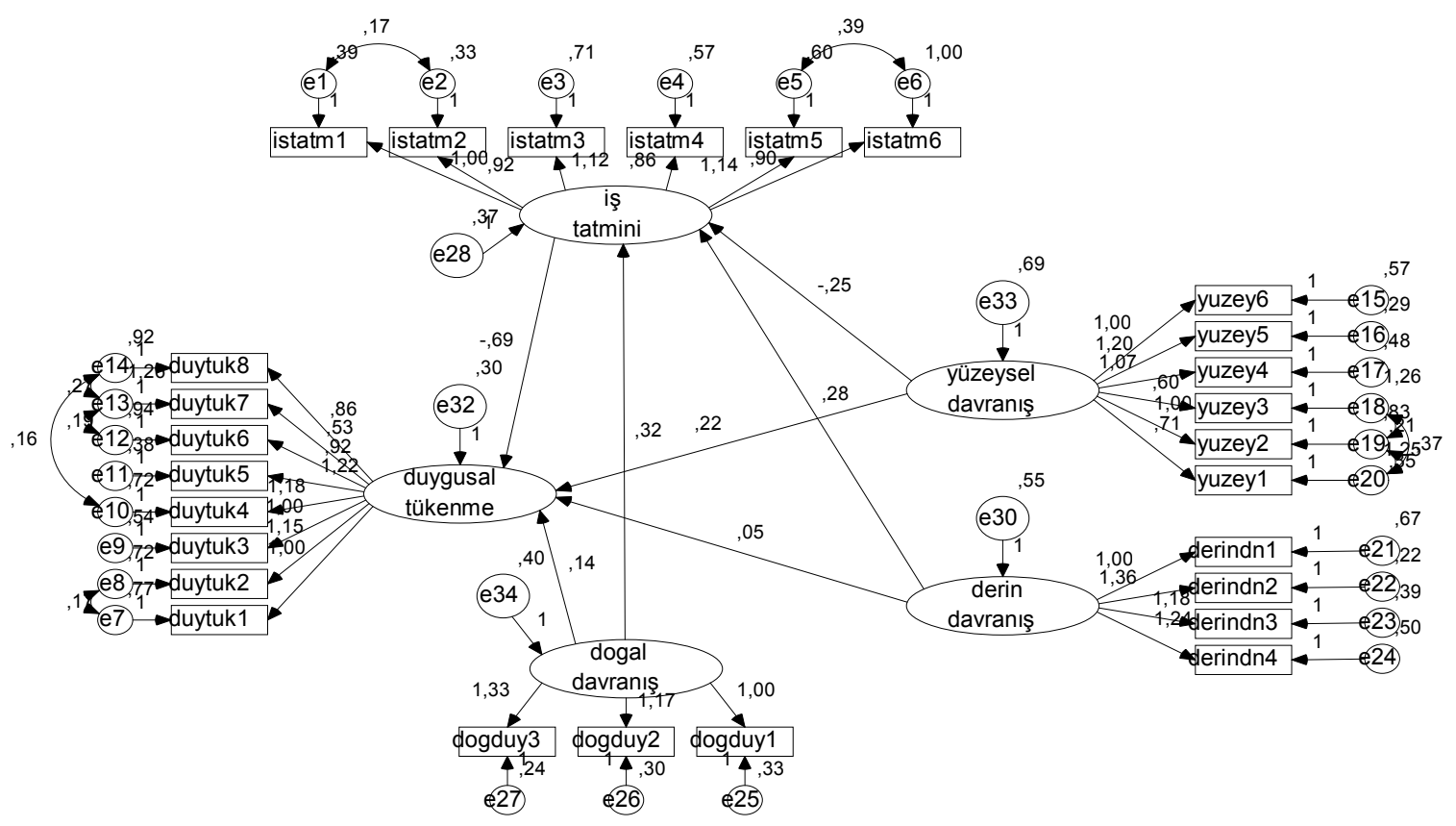

Şekil 3: İş tatmini, Duygusal Tükenme ve Duygusal Emek İlişkileri

\section{SONUÇ VE DEĞERLENDIRME}

Çalışmanın amacl; hizmet sektöründe duygusal emek, iş tatmini ve duygusal tükenme kavramları arasındaki ilişkileri incelemek ayrıca ileri sürülen hipotezlerin üretilmesinde kullanılan duygu regülasyon teorisi, duygusal olaylar teorisi ve kazanım koruma teorilerinin geçerliliklerini doğrulamaktı. Ayrıca çaIışma kapsamında iş tatmini değişkeninin, duygusal tükenme ile duygusal emek arasında aracı etkisinin olup olmadığını belirlemekti.

Yapılan bu çalışmada ilk olarak Model 1'de ileri sürülen iş tatmini ile duygusal emek arasındaki ilişkiler incelenmiştir. Elde edilen sonuçlar hizmet sektöründe çalışanların, sosyal mübadele teorisi tarafından ileri sürüldüğü gibi kendileri açısından değer verdikleri ve iş tatmini kapsamında toplanan ilerleme, sosyalleşme, ücret, vb. gibi kazanımlarının biri ya da birden fazlasını elde edebiliyorlarsa ve elde ettiklerinden memnun kalıyorlarsa, işverenin istediği derin ve doğal davranışlarla müşteriyi memnun edecekleri sonucuna ulaştırmaktadır. Çalışmadan elde edilen bu sonuç yazındaki diğer çalışmalarla karşılaştıııldığında bazıları ile paralellik (Adelman, 1995; Whartons, 1993; Bryman, 2004; Conrad ve Witte, 1994; Zapf, 2002; Johanson ve Woods, 2008; Kim, 2008; Kim ve Han, 2009), bazıları ile farklılıklar taşımaktadır (Abraham, 1998; Hochschild, 1983; Morris ve Feldman; 1997). Farklı sonuçların elde edilmesi özellikle bu veya buna benzer çalışmaların önemini daha artırmaktadır. Yazında bu konudaki boşlukların doldurulması konusunda oldukça olumlu katkılar yapacağına inanılmaktadır. Elde edilen farkIı sonuçları araştırmacılar duygusal emeğin ele alınış biçimi ile ilgili olduğunu belirtmektedirler. Yüzeysel davranış gerçek olmayan duyguları harekete geçirdiğinden iş tatminsizliğine neden olmakta buna karşın derin davranış bireyin kişisel başarı hislerini harekete geçirdiğinden sonucu iş tatmini olarak ortaya çıkabilmektedir. Bu yüzden sonuçların farklılaştığı ifade edilmektedir (Kruml ve Geddes, 2000).

Model 1'de elde edilen diğer bir sonuç yüzeyel davranış sergileyen çalışanların iş tatmini düzeylerinin düşük olduğudur. Bu sonuç işveren tarafından çalışanların beklentilerinin anlaşılmasının ne kadar önemli olduğunu göstermektedir. Eğer işveren çalışanların iş tatmini kapsamındaki beklentilerini karşılarsa bu hizmet sektöründe işletmenin rekabet avantajı elde etme konusunda pazarda oldukça önemli bir güce sahip olması anlamına gelebilecektir.

Çalışma kapsamında duygusal olaylar teorisi kullanılarak oluşturulan Model 2 ve buna bağlı olarak ortaya konan hipotezlere bakıldığında; $\mathrm{H}_{4^{\prime}} \mathrm{H}_{5}$ ve $\mathrm{H}_{6}$ hipotezlerinin desteklendiği belirlenmiştir. Elde edilen sonuçlar yazında konu ile ilgili araştırmalarla karşılaştırıldığında diğer çalışmalarla paralellik taşıdığı anlaşılmaktadır (Schaufeli ve Enzmann, 1998; Maslach, 1982; Hochschild, 1983; Kruml ve Geddes, 2000; Miller ve Koesten, 2008). Bu sonuç hizmet sektöründe tükenmişlik yaşayan çalışanların müşterilere karşı kullanacakları davranışlar ile ilgili önemli bilgiler vermektedir. Özellikle hizmet sektöründe rekabet avantajı olarak kabul gören iyi müşteri ilişkileri, tükenmişlik 
yaşayan çalışan tarafından müşteriye hizmet verirken yüzeysel davranışlarla hareket etmesi sonucu işletmenin bu konudaki avantajlarına zarar vermesi anlamına gelebilecektir. Bu yüzden çalışanların tükenmişlik ve sonuçları ile ilgili eğitim alması, tükenmişlik yaşayan arkadaşını ve yöneticilerini gerekli önlemlerin alınması konularında uyarıda bulunması, bir iç kontrol mekanizmasının oluşturulması uygun olacaktır.

Çalışma kapsamında en son oluşturulan Model 3 ve kazanımların korunması teorisi yardımıyla ileri sürülen hipotezin desteklendiği görülmektedir. Bu modelde araştırılmak istenen iş tatmininin duygusal emek ile duygusal tükenme kavramları arasındaki aracı rolü ile ilgilidir. Elde edilen sonuçlara bakıldığında iş tatmini kavramının yüzeysel davranış ile duygusal tükenme arasında yarı (partial) aracı etkisi olduğu belirlenmiştir. Buna ek olarak iş tatmini kavramının derin ve doğal davranış ile duygusal tükenme arasında tam (full) aracı etkisinin olduğu gözlemlenmiştir. Bu durum yüzeysel davranışın duygusal tükenme üzerindeki etkisini belirleyen başka örgütsel faktörlerin olduğuna işaret etmektedir. Diğer yandan iş tatmininin derin ve doğal davranış arasındaki tam aracı etki şu şekilde yorumlanabilir. Bu sonuç hizmet sektöründe rekabet avantajı olarak kabul gören derin ve doğal davranışlar çalışan tarafından sürekli kullanılsa da sonuçta tükenmişlik sendromu oluşumu iş tatmini tarafından önlendiğini göstermektedir. İş tatmini çaıışanın işinden beklediği kazanımları elde etmesi ile oluşmakta ve artmaktadır. Çalışan açısından elde edilen her kazanım vazgeçilemeyecek derecede önemli ise çalışan bu kazanımların devamını tercih edecek ve onu korumak için elinden geleni yapmak için çaba harcayacaktır. Bu durum hizmet sektöründe çalışan bireyin işinin önemli bir parçası olan ve bu sektörde önem arz eden duygusal emek kapsamında derin davranış ve doğal davranışlarını sürekli kullanmayı tercih edecek anlamına gelebilecektir. Buna ek olarak duygusal tükenmişlik yaşayan çalışan derin davranış ve doğal davranışlarını kullanırken, performansını sürekli kontrol edecek ve zaman yeterli görmeyip normalin üzerinde performans göstermesi gibi bir sonucun oluşmasına da neden olabilecektir. İş ortamında her türlü olumsuz koşul altında dahi çalışanın büyük bir özveri göstererek işini yerine getirmesinin nedeni bu olabilir. Bu nedenlerden dolayı işveren gerek normal ve gerekse normalin üstünde bir çalışan performansı elde etmek istiyor ise çalışanın iş tatminini yükseltmeyi hedeflemelidir. 


\section{KAYNAKLAR}

Abraham, R. (1998) "Emotional Dissonance in Organizations: Antecedents, Consequences, and Moderators" Genetic, Social, and General Psychology Monographs, 124(2):229-246.

Adelmann, P.K. (1995) "Emotional Labor as a Potential Source of Job Stress" Sauter et al.(eds.) Organizational Risk Factors for job Stress, Washington, American Psychological Association.

Basım, N.H. ve Begenirbaş, M. (2012) "Çalışma Yaşamında Duygusal Emek: Bir Ölçek Uyarlama Çalışması" Yönetim ve Ekonomi Dergisi Celal Bayar Üniversitesi İI.I.B.F., 19(1):77-90.

Baron, R.M. ve Kenny, D.A. (1986) "The Moderator-Mediator Variable Sistinction in Social Psychological Research: Conceptual, Strategic, and Statistical Considerations" Journal of Personality and Social Psychology, 51(6):1173-1182.

Brotheridge, C.M. ve Grandey, A.A. (2002) "Emotional Labor and Burnout: Comparing Two Perspectives of People Work" Journal of Vocational Behavior, 60:17-39.

Bussing, A. ve Glaser, J. (2000) "Four-stage Process Model of the Core Factors of Burnout: The Role of Work Stressors and Work-related Resources" Work and Stress, 14:329-346.

Bryman, A. (2004) The Disneyzation of Society, London, Sage.

Byrne, B.M. (2006) Structural Equation Modeling with EQS: Basic Concepts, Applications, and Programming, Mahwah, Lawrence Erlbaum Associates.

Cameron, S.J., Horsburgh, M.E. ve Armstrong-Stassen, M. (1994) "Job Satisfaction, Propensity to Leave, and Burnout in RNs and RNAs: A Multivariate Perspective" Canadian Journal of Nursing Administration, 7(3):43-64.

Conrad, C. ve Witte, K. (1994) Is Emotional Expression Repression Oppression? Myths of Organizational Affective Regulation, Deetz, S. (ed.) Communication Yearbook17, Thousand Oaks, Sage.

Cordes, C.L. ve Dougherty, T.W. (1993) "A Review and an Integration of Research on Job Burnout" Academy of Management Review, 18(4):621-656.

Cranny. C.J., Smith, P.C. ve Stone, E.F. (1992) Job Satisfaction: How People Feel About Their Jobs and How It Affects Their Performance, New York, Lexington Books.

Diefendorff, J.M, Croyle, M.H. ve Gosserand, R.H. (2005) "The Dimensionality and Antecedents of Emotional Labor Strategies" Journal of Vocational Behavior, 66(2):339-357.
Domadalski, T.A. (1999) "Emotion in Organizations: Main Currents” Human Relations, 52: 833-852.

Ergin, C. (1992) "Doktor ve Hemşirelerde Tükenmişlik ve Maslach Tükenmişlik Ölçeğinin Uyarlanması" Ankara Türk Psikologlar Derneği Yayını, 143-154.

Fields, D.L. (2002) Taking the Measure of Work: A Guide to Validated Scales for Organizational Research and Diagnosis, Thousand Oaks, Sage Publications.

Freudenberger, H.J. (1975) "The Staff Burnout Syndrome in Alternative Institutions" Psychotherapy: Theory, Research and Practice, 12:73-82.

Garson, G.D. (2009) "Structural Equation Modeling” http://faculty.chass.ncsu.edu/garson/PA765/structur. htm, (26 Mart 2014),

George, J.M. ve Jones, G.R. (1997) "Experiencing work: Values, Attitudes, and Moods" Human Relations, 50(4):393-416.

Grandey, A.A. (2003) "When the Show Must Go On: Surface and Deep Acting as Determinants of Emotional Exhaustion and Peer-rated Service Delivery" Academy of Management Journal 46(1):86-96

Grandey, A.A. (2000) "Emotion Regulation in the Workplace: A New Way to Conceptualize Emotional Labor" Journal of Occupational Health Psychology, 5:95110.

Grandey, A., Fisk, G., Mattila, A., Jansen, K.J. ve Sideman, L. (2005) "Is Service With a Smile Enough? Authenticity of Positive Displays During Service Encounters" Organizational Behavior \& Human Decision Processes, 96(1):38-55.

Gross, J. (1998b) “The Emerging Field of Emotion Regulation: An Integrative Review" Review of General Psychology, 2(3):271-299.

Grönroos, C. (2007) Service Management and Marketing: Customer Management in Service Competition, $3^{\text {th }}$ Edition, Chichester Wiley.

Hobfoll, S.E. (1989) "Conservation of Resources: A New Attempt at Conceptualizing Stress" American Psychologist, 44:513-524.

Hobfoll, S.E. (1998) Stress, Culture and Community. The Psychology And Philosophy Of Stres,. New York, Plenum.

Hobfoll, S.E. (2001) "The Influence of Culture, Community and the Nested-self in the Stress

Process: Advancing Conservation of Resources theory" Journal of Applied Psychology, 50: 337-396. 
Hochschild, A.R. (1983) The Managed Heart: The Commercialization of Feeling, Berkeley, University of California Press.

Jackson, S.E., Schwab, R.L. ve Schuler, R.S. (1986) "Toward an Understanding of the Burnout Phenomenon" Journal of Applied Psychology, 71(4):630-640.

Johanson, M.M. ve Woods, R.H. (2008) "Recognizing the Emotional Element in Service Excellence" Cornell Hospitality Quarterly 49(3):310-316.

Jöreskog, K., Sörbom, D. (2001) LISREL 8: User's Reference Guide, Scientific Software International Inc.

Kim, M.J. ve Han, S.Y. (2009) "Relationship Between Emotional Labor Consequences and Employees' Coping Strategy" Asia Pacific Journal of Tourism Research 14(3):225-239.

Kim, H.J.(2008) "Hotel Service Providers' Emotional Labor: The Antecedents and Effectson Burnout" International Journal of Hospitality Management 27(2):151-161.

Kohn, M.L. ve Schooler, C. (1982) "Job Conditions and Personality: A Longitudinal Assessment of their Reciprocal Effects" American Journal of Sociology, 87:1257-1286.

Kruml, S.M. ve Geddes, D. (2000) "Exploring the Dimensions of Emotional Labor: The Heart of Hochschild's Work" Management Communication Quarterly 14(1):8-49.

Kula, S. (2011) "Occupational Stress and WorkRelated Wellbeing of Turkish National Police (TNP) Members" University of Central Florida, Orlando.

Lee, L.T. ve Ashforth, B.E. (1996) "A Meta-analytic Examination of The Correlates of The Three Dimension of Job Burnout" Journal of Applied Psychology, 81, 123-133.

Lin, S.P. (2000) "A Study of the Development of Emotional Labour Loading Scale" Sun Yat-Sen Management Review 8(3):427-447.

Makanjee, R.C., Hartzer, Y. ve Uys, I. (2006) "The Effect of Perceived Organizational 133 Support on Organizational Commitment of Diagnostic Imaging Radiographers" Radiography, 12(2):118-126.

Maslach, C. ve Jackson, S.E. (1986) Maslach Burnout Inventory Manual, $2^{\text {nd }}$ Edition, Palo Alto, Consulting Psychologists Press.

Maslach, C. (1982) Burnout: The Cost of Caring, Englewood Cliffs, Prentice-Hall.

Mastracci, S.H. ve Newman, M.A. ve Guy, M.E. (2006) "Appraising Emotional Work: Determining Whether Emotional Labor is Valued in Government Jobs" American Review of Public Administration, 36(2):123-138.
Mattila, A.S. ve Enz, C.A. (2002) "The Role of Emotions in Service Encounters" Journal of Service Research, 4:268-277.

Miller, K.I. ve Koesten, J. (2008) "Financial Feelings: An Investigation of Emotion and Communication in The Workplace" Journal of Applied Communication Research, 36:8-32.

Morris, A.J. ve Feldman, D.C. (1996) "The Dimensions, Antecedents, and Consequences of Emotional Labor" Academy of Management Review, 21:98-1010.

Morris, A.J. ve Feldman, D.C. (1997) "Managing Emotions in the Workplace" Journal of Managerial Issues, 9(3):257-274.

Ostroff, C. (1992) "The Relationship Between Satisfaction, Attitudes, and Performance: An Organizational Level Analysis" Journal of Applied Psychology, 77(6):963-974.

Parnell, J.A. ve Crandall, W. (2003) "Propensity for Participative Decision-making, Job satisfaction, Organizational Commitment, Organizational Citizenship Behavior, and Intentions to Leave Among Egyptian Managers" The Multinational Business Review, 11(1): 45-65.

Porter, L.W. (1964) Organizational Patterns of Managerial Job Attitudes, New York, American Foundation for Management Research.

Pugh, S.D. (2001) "Service With a Smile: Emotional Contagion in The Service Encounter" Academy of Management Journal, 44:1018-1027.

Pugliesi, K. (1999) "The Consequences of Emotional Labor: Effects on Work Stress, Job Satisfaction, and WeilBeing" Motivation and Emotion, 33(2):125-154.

Rafaeli, A. ve Sutton, R. (1987) "Expression of Emotionas Part of the Work Role" Academy of ManagementReview, 12(1):23-37.

Schaufeli, W.B., Maslach, C. ve Marek, T. (1993) "The Future of Burnout" Schaufeli et al. (eds.) Professional Burnout: Recent Developments in Theory And Research, Washington, Taylor \& Francis.

Schaufeli, W.B. ve Enzmann, D. (1998) The Burnout Companion to Study and Practice: A Critical Analysis, London, Taylor \& Francis.

Schumacker, R.E. ve Lomax, R.G. (2004) A Beginner's Guide to Structural Equation Modeling, 2 nd Edition, Mahwah, Lawrence Erlbaum Associates,

Schilling, C. (2003) The Body and Social Theory, 2nd Edition. London, Sage Publication.

Shani, A., Uriely, N., Reichel, A. ve Ginsburg, L. (2014) "Emotional Labor in the Hospitality Industry: The Influence of Contextual Factor." International Journal of Hospitality Management, 37:150-158. 
Spector, P.E. (1985) "Measurement of Human Service Staff Satisfaction: Development of the Job Satisfaction Survey" American Journal of Community Psychology, 13(6):693-713.

Steinberg, R.J. ve Figart, D.M. (1999) "Emotional Labor since. The Managed Heart" The Annals of the American Academy of Political and Social Science, 561(1):8-26.

Taylor, S.J. (2002) Effects of a Nonverbal Skill Training Program on Perceptions of Personal Charisma, Unpublished Doctoral Dissertation, University of California, Riverside.

Testa, M.R. (2001) "Testa Organizational Commitment Job Satisfaction and Effort in the Service Environment" The Journal of Psychology, 135(2):226-236.

Tolich, M.B. (1993) "Alienating and Liberating Emotions at Work: Supermarket Clerks' Performance of Customer Service" Journal of Contemporary Ethnography, 22:361-381.

Tsai, W.C. (2001) "Determinants and Consequences of Employee Displayed Positive Emotions" Journal of Management, 27:497-512.

Tümkaya S., Cam, S. ve Cavuşoğlu, I. (2009) "Tükenmişlik Ölçeği Kısa Versiyonu’nun Türkçeye Uyarlama, Geçerlik ve Güvenirlik Çalışması” Ç.U. Sosyal Bilimler Enstitüsü Dergisi, 18(1):387-398.

Uryan, Y. (2010) "Organizational Safety Culture and Individual Safety Behavior: A Case Study of The Turkish National Police Aviation Department" Unpublished Dissertation Orlando,University of Central Florida.

Vandenberg, R.J. ve Lance, C.E. (1992) "Examining the Causal Order of Job Satisfaction and Organizational Commitment" Journal of Management, 18(1):153-167.

Van Dijk, P.A., Smith, L.D.G. ve Cooper. B.K. (2011) "Are you for real? An Evaluation of the Relationship Between Emotional Labour and Visitor Outcomes" Tourism Management, 32(1): 39-45.

Wan, T.T. (2002) Evidence-based Health Care Management: Multivariate Modeling Approaches, Netherlands, Springer.

Wegge, J., Schmidt, K., Parkes, ve Dick, R. (2007) "Taking a Sickie: Job Satisfaction and Job Involvement as Interactive Predictors in Absenteeism in a Public Organization" Journal of occupational and organizational psychology, 80:77-89.
Weiss, H. ve Cropanzano, R. (1996) "Affective Events Theory: A Theoretical Discussion of the Structure, Causes, and Consequences of Affective Experiences at Work" Research in Organizational Behavior, 18:1-74.

Wharton, A.S. (1993) "The Affective Cconsequences of Service Work: Managing Emo-tions on the Job" Work and Occupations 20(2):205-232.

Wharton, A.S. (1996) "Service With A Smile: Understanding The Consequences of Emotional Labor". MacDonald et al.(eds.) Working in The Service Society, Philadelphia, Temple University Press.

Wharton, A.S. ve Erickson, R. J. (1995) "The Consequences of Caring: Exploring the Links Between Women's Job and Family Emotion Work" The Sociological Quarterly, 36:273-296.

Williams, L.J. ve Anderson, S. E. (1991) "Job Satisfaction and Organizational Commitment as Predictors of Organizational Citizenship and In-role Behaviors" Journal of Management, 17(3):601-617.

Wright, T.A., ve Cropanzano, R. (1998) "Emotional Exhaustion as a Predictor of Job Performance and Voluntary Turnover" Journal of Applied Psychology, 83:486-493.

Wright, T.A. ve Bonett, D.G. (1997) "The Contribution of Burnout to Work Performance" Journal of Organizational Behavior, 18:491-499.

Wolcott-Burnam, S.B. (2004) "Examining Emotional Labor from an Inter Actionist Perspective: The Impact of Work Conditions on The Relationship Between Emotional Labor and Outcome" Unpublished Dissertation.

Wolpin, J., Burke, R.J. ve Greenglass, E.R. (1991) "Is Job Satisfaction an Antecedent or a Consequence of Psychology Burnout?” Human Relations, 44(2):193-209.

Wong, J. ve Wang, C. (2009) "Emotional Labor of The Tour Leaders: An Exploratory Study" Tourism Management 30(2):249-259.

Zapf, D. (2002) "Emotion Work and Psychological Wellbeing.A Review of the Literature and Some Conceptual Consideration" Human Resources Management Review, 12:237-268. 
